\title{
Medienanalytische Betrachtungen zu Claus Peymanns Verfilmung der "Hermannsschlacht" nach Heinrich von Kleist
}

\author{
[A media-analytic view on Claus Peymann's film about Heinrich von Kleist's \\ "Hermannsschlacht"]
}

\begin{abstract}
This paper describes interpretations of Heinrich von Kleist's Hermannsschlacht (title in English: The Battle of the Teutoburg Forest). Historically there have been four different types of interpretation: those that praise both content and form, those that express dislike of both content and form, those that praise the content but dislike the form, and those that inversely express dislike for the content but admiration for the form. It is argued here that Claus Peymann's interpretation, as seen in his film, goes contrary to these traditional ways of dealing with Hermannsschlacht, since Peymann's interpretation obviously respects Kleist's text but interprets Hermansschlacht as a text in favor of peace, not war.
\end{abstract}

Keywords: Heinrich von Kleist; Die Hermannsschlacht; war and peace; content and form

Zusammenfassung: Der Artikel beschreibt den bisher zu beobachtenden Umgang mit Heinrich von Kleists Stück "Die Hermannsschlacht". Demnach gab es vier Bewertungen: Bewunderung für Werk und Form, Ablehnung von Werk und Form, sowie die Kombinationen der Bewunderung des Werks bei gleichzeitiger Ablehnung der Form, und schließlich die umgekehrte Herangehensweise: Bewunderung der Form bei gleichzeitiger Ablehnung des Inhalts. Der Artikel argumentiert, dass Claus Peymanns Inszenierung diese vier klassischen Bewertungen durchbrochen hat. Er bewundert offenbar Kleists Werk, inszeniert es aber ,gegen den Autor' als „Hermannsschlacht für den Frieden”. Die Argumentation erfolgt anhand der Verfilmung der Peymannschen Aufführung.

Schlüsselwörter: Heinrich von Kleist, "Die Hermannsschlacht", Krieg und Frieden, Inhalt und Form

\footnotetext{
${ }^{1}$ Prof. Dr. habil. Hans W. Giessen, Universität des Saarlandes. Email: h.giessen@ gmx.net
} 


\section{Allgemeine Vorbemerkung}

Im Jahr 1984 hat das Zweite Deutsche Fernsehen einen Film in Auftrag gegeben, der die wichtige Inszenierung der Hermannsschlacht von Claus Peymann am Schauspielhaus Bochum zum Gegenstand hatte (PEYMANN 1984). Die Inszenierung bedeutete einen (Wende-)Punkt in der Hermannsschlacht-Rezeption. Der Film ermöglichte die Auseinandersetzung mit dieser wirkungsgeschichtlich bedeutsamen Aufführung auch für denjenigen, dem der Besuch des Bochumer Schauspielhauses nicht möglich war; sie dokumentiert eine ansonsten allenfalls aus der Erinnerung (und der Literatur) rekonstruierbare, aufgrund ihres Ansatzes aber bleibende Auseinandersetzung mit der Hermannsschlacht Heinrich von Kleists, die ohne diesen Film nicht mehr (so gut) analysierbar wäre.

Der Film ist allerdings mehr als ,nur eine Abfilmung der Inszenierung. Die Bearbeitung und Regie erfolgte durch den Regisseur der Inszenierung selbst, durch Claus Peymann - der filmische Mittel bewusst eingesetzt hat, um sein Konzept in dem anderen Medium und vermittels dessen spezifischer Eigenschaften zu verdeutlichen. Von daher ist die Beschäftigung mit dieser Verfilmung auch als allgemeiner Beitrag über Möglichkeiten und Chancen einer filmischen Werkdeutung zu sehen.

Dieser Beitrag erschließt mit dem filmischen Medium eine neue, für die Rezeption der Hermannsschlacht wichtige Quelle. Vor diesem Hintergrund soll er auch einen Beitrag zur Bewertung des Werkes und seiner Rezeptionsgeschichte leisten.

\section{Der ,Hermann'-Mythos}

Der Mythos der Hermannsschlacht als deutsch-nationales Ereignis entstand wohl erst gegen Ende des 18. Jahrhunderts, zusammen mit der Entstehung des deutschen Nationalgedankens (dazu und zum folgenden beispielsweise WINKLER 1978, VINKEN 2011); zuvor scheint die spezifische Eigenschaft des ,Deutsch-Seins' zwar als (gegenüber anderen) unterscheidendes und (gegenüber anderen Deutschen) kulturell verbindendes Merkmal empfunden worden $\mathrm{zu}$ sein, nicht aber als ein politisches Handeln motivierendes Moment. Das Fehlen nationalistischer Gefühle ist im übrigen 
wohl bis dahin für alle ,Nationen' typisch gewesen - so bedeutete beispielsweise die Eroberung Straßburgs durch Louis XIV. im Jahr 1681 ja auch keineswegs eine Romanisierung der Stadt, und so war etwa die Straßburger Universität trotz französischer Oberhoheit noch weit länger als ein Jahrhundert eine ,deutsche“ Universität, an der zum Beispiel Johann Wolfgang Goethe noch rund hundert Jahre später, von 1770 bis 1771 studierte (vergleiche beispielsweise die Darstellung Ernst Traumanns aus dem Jahr 1923, die deshalb besonders aussagekräftig ist, weil sie aus einer Zeit stammt, in der eine positive Würdigung alles Deutschen noch sehr wichtig war). Die Idee eines Nationalstaates, der alle Mitglieder einer Nation umfassen sollte (aber zunächst auch nur die Mitglieder der eigenen Nation und niemanden anderes) wurde erst gegen Ende des 18. Jahrhunderts populär, im Zuge der geistesgeschichtlichen Umwälzungen in dieser Epoche. In Deutschland, das seine politische Einheit bereits im Mittelalter verloren hatte, verdrängte der Nationalstaatsgedanke bald die weiteren Ideale jener Epoche: dies wurde spätestens beim Wartburgfest 1817 offensichtlich (BARDONG 1993). Dieses Nationalgefühl steigerte sich während der napoleonischen Besetzung Deutschlands (und verursacht durch sie) zum Nationalismus. Es entstammte mithin der Ideenwelt der französischen Revolution, wandelte und veränderte sich aber aus dem Gefühl der vermeintlichen oder wirklichen Not des deutschen Vaterlands - verursacht durch eben die Truppen der Franzosen, die in Folge der Revolution nach Deutschland drangen.

Diese Prozesse lassen sich eindrucksvoll am Wandel des ,Hermann“-Mythos darstellen, an der Beschreibung der Veränderungen, denen der Stoff unterworfen war; ihm kommt daher eine Indikatorenfunktion für die Entwicklung, Geschichte und Bedeutung nationalistischen Gedankenguts in Deutschland zu. Dabei ist deutlich, dass der Nationalgedanke selbst zunächst nicht im Vordergrund bei Bearbeitungen des Stoffes stand - wohl aber die Abgrenzung gegenüber anderen Völkern, die auf die gesellschaftliche und politische Ordnung in Deutschland Einfluss nehmen wollten. Wesentlich ist diese negative Begründung, die Abwehrhaltung; deren Stärkung (und positiven Fundierung) sollte der Mythos allerdings schon am Anfang dienen.

Die Germania des Tacitus wurde im Jahre 1470 wiederentdeckt; im Zusammenhang mit dem die Renaissance charakterisierenden Interesse an der klassischen Vergangenheit als der Epoche, die einen ersten kulturellen Höhepunkt für Europa bedeutet habe, an den es nun anzuschließen gelte. Für die Deutschen bedeutete 
Giessen, H. W. - Medienanalytische Betrachtungen

dies auch, sich ihrer Eigen-Art bewusst zu werden, die nun für die Antike gesichert (und von Tacitus mit überwiegend positiven Wertungen versehen) war. Aus diesem Grund wurde die „Germania'“ schnell und breit rezipiert; die Rezeption war insofern bereits politisch motiviert: allerdings eben (noch) nicht nationalistisch, sondern modernistischlegitimativ.

In diesen Zusammenhang fällt auch die erste Beschäftigung mit dem Thema der Hermannsschlacht. Der Humanist Ulrich von Hutten war im Kontext der Reformationswirren ein starker Kritiker der römisch-katholischen Kirche und des zeitgenössischen Papsttums; er hat die erste Bearbeitung des Stoffes vorgelegt, die posthum 1529 unter dem Titel Arminius. Dialogus Huttenicus, quo homo patriae amantissimus, Germanorum laudem celebravit erschienen ist. Auch hier ist die politische Funktion eindeutig; gleich in der ersten literarischen Verwendung wird der Stoff zur Abgrenzung genutzt: Rom ist die Metonymie für die katholische Kirche, dagegen verweisen Anspielungen auf eine Gleichsetzung der ,Germanen“ mit der Reformation - womit allerdings auch deutlich ist, dass die Abgrenzung nicht aus nationalistischen, sondern aus politisch-gesellschaftlichen Gründen erfolgt. Ein wichtiges Indiz für das Zielpublikum und damit die politische Intention des Werkes ist, dass es zur Gänze in lateinischer Sprache geschrieben wurde: Es richtete sich an ein gelehrtes Publikum, es beabsichtigte die intellektuelle Auseinandersetzung, nicht die möglicherweise demagogische Einflussnahme auf das ,deutsche Volk', das das Werk bereits aus sprachlichen Gründen gar nicht verstehen konnte.

Auch die weiteren Beschäftigungen mit dem Stoff der Hermannsschlacht waren nicht von nationalistischen Absichten geprägt. Daniel Caspar von Lohenstein gestaltete eine 1689/90 erschienene Barockversion, Großmüthiger Feldherr Arminius oder Hermann, Als ein tapfferer Beschirmer der deutschen Freyheit, Nebst seiner Durchlauchtigten Thußnelda In einer sinnreichen Staats- Liebes- und HeldenGeschichte Dem Vaterlande zu Liebe Dem deutschen Adel aber zu Ehren und rühmlichen Nachfolge In Zwey Theilen vorgestellet, auf über 3.000 Seiten. Seine Stoffgestaltung ist humanistisch-bürgerlich; ein bestimmendes politisches Anliegen kann nicht erkannt werden. Lohenstein ist vor allem deshalb rezeptionsgeschichtlich wichtig, weil sein Roman im gesamten 18. Jahrhundert vielgelesen war und somit das Thema populär gemacht beziehungsweise gehalten hat. Es folgten deshalb weitere Bearbeitungen, teilweise von noch heute bekannten Autoren, wie 1751 von Wieland 
Giessen, H. W. - Medienanalytische Betrachtungen

(Hermann, Epos) oder 1761 von Johann Elias Schlegel (Hermann, Trauerspiel). Schlegel war auf Schulpforta ein Mitschüler Klopstocks; beide haben das Thema bearbeitet, Klopstock 1769 als Bardiet (Hermanns Schlacht, Ein Bardiet für die Schaubühne). Bis dahin sind alle Bearbeitungen des Motivs von den Gedanken der Aufklärung getragen gewesen (SENGLE 1952: 12ff.); dagegen passt sich Klopstock dem Zeitgeist an und gestaltet das Thema vor einem christlich-pietistischen Hintergrund.

Auch diese Bearbeitung war weit verbreitet und sicherlich auch Heinrich von Kleist bekannt. Wie populär und verbreitet das Motiv inzwischen war (und wie wenig noch deutsch-national besetzt), demonstriert die Tatsache, dass sich auch Bearbeitungen in anderen Sprach- und Kulturkreisen finden: So schuf beispielsweise der Italiener Ippolito Pindemonte 1804 eine an klassischen Mustern orientierte Tragödie in fünf Akten mit dem Titel Arminio. Und auch in Deutschland hörte die Bearbeitung des Stoffes mit Kleists Fassung der Hermannsschlacht nicht auf; aufgrund der geringen Verbreitung von Kleists Werk war seine Tendenz für andere Autoren auch noch nicht belastend - beispielsweise für Christian Dietrich Grabbe, der 1838 Die Hermannsschlacht als ,Geschichtsdrama in Prosa' vorlegte.

Die nationalistische Festlegung des Hermannsmythos bestimmt allerdings die Beschäftigung mit der Hermannsschlacht Heinrich von Kleists, der ihn auf eine Art und Weise genutzt hat, wie dies erst wieder durch den Nationalsozialismus geschehen ist (der sich demnach der Kleistschen Hermannsschlacht auch bedient hat). Kleist setzt ihn so ein, wie er weitgehend noch heute - vor allem aufgrund der mörderischen Folgen seiner politischen Nutzung - die Diskussion prägt: als nationalistischer, fremdenfeindlicher und hasserfüllter Legitimationsmythos.

Gerade weil sie nationalistische Wirkungsabsichten besitzt, zeichnet die ,Hermannsschlacht` Heinrich von Kleists nicht das Bild des historischen Ereignisses (was, wie gezeigt worden ist, anfangs des neunzehnten Jahrhunderts nicht mehr möglich war), sondern nutzt sie zu emotional-diffuser Propaganda. Bereits im neunzehnten Jahrhundert wurde deshalb über die genaue Zuordnung der Germanenfürsten in Kleists Hermannsschlacht gerätselt. Einigkeit herrschte zumindest darüber, dass die Römer des Stückes die Franzosen (für alle, mit zahlreichen Belegen: HEMPEL 1930: 6ff.) und die ,kleineren“ Germanenführer die Rheinbundfürsten repräsentierten (vergleiche das Dahlmann-Zitat bei STRELLER 1978: 686 oder erneut HEMPEL 1930: 6). Zweifel hinsichtlich der Zuordnung der Hauptvertreter der Germanen sind aber unvermeidbar 
(SCHÄFER 1993). So könnte Hermann Preußen und Marbod Österreich repräsentieren (ZoLLING 1885). Andererseits waren die Preußen in der aktuellen historischen Situation gerade ein (und sei es auch nur taktisch motiviertes) Bündnis mit Frankreich eingegangen (wie im Stück aber die Sueben mit den Römern), während Kleists Hoffnung ja bei den Österreichern lag, (so, wie die Hoffnung der freiheitsliebenden Germanen in der ,Hermannsschlacht“ bei den Cheruskern liegt). Dass Kleist politische Erfolge nur noch von den Österreichern erwartete, demonstriert ja eindrucksvoll die Tatsache, dass er sich 1809 mit Dahlmann auf den Weg nach Wien machte, um dort Zeuge der Ereignisse zu werden: „Wir wollten nicht bei den Sachsen bleiben, die unter Bernadotte gegen Deutschland zogen, Deutschland, das wir umso tiefer im Herzen trugen, je weniger es draußen zu finden war. Unser Vorsatz war, von Böhmen aus nach allen Kräften dahin zu wirken, dass aus dem österreichischen Kriege ein deutscher werde.“ (zitiert bei HORN 1980: 73).

Fraglich ist mithin, ob konkrete Zuweisungen möglich, fraglich ist auch, ob sie notwendig sind. Immerhin wird allgemein akzeptiert, dass Kleist mit der historischen Vorlage sehr frei umgegangen war (STRELLER 1978: 681) - doch war er ja zumindest insoweit an den Hermann-Mythos gebunden, als er den Träger dieses Mythos als Hauptperson einsetzen musste, von dem die Initiative zur Schlacht auszugehen und der die Schlacht als Sieger zu verlassen hatte. Eine andere Verwendung der HermannsFigur hätte dem Mythos widersprochen und damit seine Verwendung zunichte gemacht - offenbar hat Kleist ihn aber bewusst eingesetzt. Mit der Festlegung der Figur des Hermann von außen entwickelten sich die anderen Personen nahezu zwangsläufig, zumindest bezüglich ihres Verhältnisses zu Hermann und zu der von ihm vertretenen Sache. Aus diesem Grund ist die Frage nach konkreten Analogien zwar historisch interessant, wird aber der Hermannsschlacht - auch und gerade als ,Tendenzstück ‘ nicht gerecht. Eine Äußerung Friedrich Christoph Dahlmanns in einem bekannten Brief an den Literaturhistoriker Georg Gottfried Gervinus - „[Die ,Hermannsschlacht $\left.{ }^{`}\right]$ hat [...] historischen Wert; treffender kann der hündische Rheinbundsgeist, wie er damals herrschte (Sie haben das nicht erlebt) gar nicht geschildert werden. Damals verstand jeder die Beziehungen, wer der Fürst Aristan sei, der zuletzt zum Tode geführt wird, wer die wären, die durch Wichtigtun und Botenschicken das Vaterland zu retten meinten [...]“" (zitiert bei STRELLER 1978: 686; HEMPEL 1930: 6) - deutet immerhin an, dass Nebenfiguren (wie der Fürst Aristan) zugeordnet werden können, und sicherlich 
Giessen, H. W. - Medienanalytische Betrachtungen

auch die Atmosphäre, die politischen Empfindungen des Jahres 1808, des Entstehungsjahres der Hermannsschlacht - und dies war offensichtlich Kleists eigentliche Absicht. Die politische Absicht Kleists verdeutlicht sich demnach am Handeln der Protagonisten: mit Hermann soll sich das Publikum offenbar identifizieren - er zeichnet sich durch seinen Römer- (also: Franzosen-) Hass aus; auch Marbod und die Sueben teilen diese Einstellung.

\section{Rezeptions- und Aufführungsgeschichte unter besonderer Berücksichtigung der leitenden Prinzipien, samt einem kritischen Blick auf Probleme der Werkinterpretation}

\section{1}

Die aktuelle politische Wirkungsabsicht der ,Hermannsschlacht' wurde bereits von Kleists Zeitgenossen deutlich empfunden (STRELLER 1978: 683); sie bestimmte demnach auch die Bewertung durch die Rezipienten. Offenbar aufgrund dieser politischen Wirkungsabsicht konnte das Werk zunächst auch nicht in Druck gehen; zu Kleists Lebzeiten gab es deshalb keine gedruckte Fassung (der erste Abdruck erfolgte fragmentarisch 1818 in den Zeitschwingen, und die erste Drucklegung 1821 in der Tieckschen Ausgabe der Hinterlassenen Schriften Heinrich von Kleists). Aufgrund der politischen Aussage war auch eine Aufführung in den deutschen Ländern, auf die Napoleon Einfluss hatte, chancenlos. Kleist selbst sah nur in Österreich die Möglichkeit einer Präsentation auf der Bühne. Bereits am 1. Januar 1809 bot er sein Drama über den österreichischen Dichter und Hofsekretär Heinrich Josef von Collin, der über gute Kontakte verfügte, dem Wiener Hofburgtheater an; seine Eile lag gerade in der beabsichtigten politischen Wirkung begründet. Die napoleonischen Siege über Österreich im Sommer 1809 zerstörten aber alle Aufführungspläne; erst im Januar 1810 konnte Kleist diesbezüglich wieder bei Collin nachfragen. Dessen Versuche scheiterten allerdings, wie im Übrigen auch weitere Pläne im darauffolgenden Jahr, das Stück im Theater an der Wien unterzubringen. So kam es zu Lebzeiten Kleists zu keiner Aufführung (STRELLER 1978: 683). Die Uraufführung erfolgte erst nahezu dreißig Jahre später, am 29. August 1839, durch das Detmolder Hoftheater in Pyrmont; am 20. Oktober 1839 wurde die Aufführung in Münster wiederholt. Die Einstudierung geriet 
Giessen, H. W. - Medienanalytische Betrachtungen

aber schnell wieder in Vergessenheit, denn lange Zeit wurde eine Breslauer Inszenierung aus dem Jahr 1860, noch einmal zwanzig Jahre später, als erste Aufführung angesehen. Bemerkenswert ist, dass diese Einstudierung - insgesamt offenbar ein großer Erfolg - zuvor (durch Feodor Wehl) bearbeitet wurde, der unter ästhetischen Gesichtspunkten „die schärfsten Kanten abgeschliffen“ hatte (ZOLLING 1885). So gesellt sich zum politischen Aspekt ein zweiter: derjenige der Form, der, eng verbunden mit dem ersten, die Rezeptions- und Aufführungsgeschichte der Hermannsschlacht stark beeinflusst hat.

Unmittelbare Bekannte Kleists lobten die Intention der Hermannsschlacht - was wohl auch mit ihrer (sicherlich durch gemeinsame Überzeugungen getragenen) Freundschaft zu Kleist zusammenhängt und mithin den inhaltlichen Aspekt in den Vordergrund treten lässt. Kleists enger Freund Friedrich Christoph Dahlmann urteilte beispielsweise: „Für [Heinrich von Kleists] bestes Werk halte ich die am wenigsten besprochene ,Hermannsschlacht““ (STRELLER 1978: 686; HEMPEL 1930: 6); ähnlich schätzte Matthäus von Collin von den in der ersten Ausgabe der Werke Kleists (1821) gedruckten Dramen die Hermannsschlacht am höchsten ein (COLLIN 1822).

Die positive Wertung der beiden, die auf persönlicher wie politischer Übereinstimmung fußte, hatte allerdings auch Folgen für die formale Einschätzung. Collin schrieb an derselben Stelle, die Zerstückelung der Hally sei würdig und groß, die Bestrafung des Ventidius sei angemessen: „Die Wahrheit des Gefühls ist hier nicht

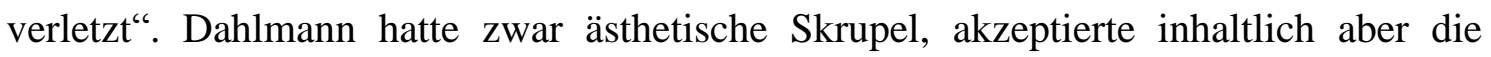
Position Kleists.

Die Aufnahme der Hermannsschlacht war insgesamt aber gerade aus diesen ästhetischen Gründen negativ, und so bemerkte Collin, Kleist habe sich - offenbar ja ganz im Gegensatz zu seiner Absicht - mit diesem Stück zu seinem Zeitalter in Opposition gestellt. Die Kritik machte vor dem Bekanntenkreis Kleists nicht halt; sie wird beispielsweise von Clemens Brentano geteilt, der die Hermannsschlacht bei Marie von Kleist kennengelernt hatte (STRELLER 1978 687). In der ersten Hälfte des neunzehnten Jahrhunderts überwogen die eher abwägenden, vorsichtigen Urteile. Ludwig Tieck, der die hinterlassenen Schriften Heinrich von Kleists herausgab, teilte den nationalen Ansatz, hatte aber Bedenken insbesondere bezüglich der bereits geschilderten Details, die, seiner Meinung nach, die Wirkung auf viele Leser beeinträchtigen könnten. Der preußische Historiker Heinrich von Treitschke vertrat eine 
ähnliche Position: er äußerte sich begeistert über den ,staatsmännischen Barbaren Hermann', aber insgesamt irritierte ihn die ,maßlose Leidenschaft‘, und die Bärenszene fand er gar ,empörend‘ (TREITSCHKE 1858).

Die Beurteilungen des Werks lassen sich also auf die genannten zwei Positionen, den inhaltlich-politischen und den ästhetisch-formalen - und damit auf die folgenden vier Konstellationen reduzieren.

Zunächst: Entweder wird die nationale Haltung des Stückes, seine politische Grundtendenz geteilt - oder heftig abgelehnt; der politischen Aussage kritisch gegenüberstehende Rezipienten schlossen in ihre Kritik häufig auch formale und ästhetische Punkte mit ein (und fanden daher überhaupt keinen positiven Aspekt in der Hermannsschlacht); umgekehrt wird die formal-ästhetische Seite von den Befürwortern durch die inhaltliche Aussage immer wieder legitimiert. Zwei weitere Positionen differenzieren zwischen Inhalt und Form - und bewundern das jeweils eine, ohne das andere gerechtfertigt zu sehen. Die Beschäftigung mit der Problematik von Form und Aussage prägt auch die hier besprochene Verfilmung; die Rezeption dieses Kriterienpaares soll deshalb zunächst in ihren wesentlichen Einschätzungen und Bewertungen weiter verfolgt und dargestellt werden.

Ein Beispiel für die absolute Kritik stellt der liberale Kleist-Biograph Adolf WILlBRANDT dar, der (1863) etwa für die Tat der Thusnelda keine hinreichend begründete Motivation sah und eine solche Tat auch grundsätzlich nicht legitimieren zu können meinte: Er bewertete die ,Hermannsschlacht‘ als ,peinliches Merkmal der inneren Erkrankung, wo ein Kultus der Rache sein fürchterliches Spiel` treibe. Ähnlich äußerte sich 1878 beispielsweise auch Karl GUTZKOw.

Auch bei vielen Rezipienten des neunzehnten Jahrhunderts, die in ihrer politischen Einstellung eher national geprägt waren und die daher mit der Grundtendenz des Werkes sympathisierten, stieß die ,Hermannsschlacht“ aus ästhetischen und formalen Gründen auf Ablehnung: sie entsprach zumeist nicht ihrem literarischen Verständnis, den herrschenden Geschmacksvorstellungen. Beispielhaft ist hier die Ansicht Julian Schmidts, der ja eine erste kritische Ausgabe besorgte - er würdigte 1876 den deutschen Patriotismus der ,Hermannsschlacht" und sah das Stück durchaus historisch, aber eben nicht dramatisch gerechtfertigt: , [...] einige wilde Scenen [...] hätten füglich wegbleiben können“ (SCHMIDT 1876: 593). Im Gegensatz zur zunächst dargestellten Position, die weder Form noch Aussage positiv bewertet, zeigt sich hier 
eine inhaltliche Übereinstimmung; die Kritik bezieht sich (lediglich) auf die Form. Diese Position prägt auch die weiteren Inszenierungen: Nach dem DeutschFranzösischen Krieg und offensichtlich in Zusammenhang mit der daraus resultierenden patriotischen Zeitstimmung wurde die ,Hermannsschlacht' vermehrt aufgeführt. Seit 1875 spielte das Meiningensche Hoftheater die Originalfassung des Werkes; 1876 folgte die Berliner Inszenierung Rudolf Genées, die „das allzu Schroffe und Wilde beseitigt oder doch gemildert" (HEMPEL 1930: 9) hatte. Nun fand die „Hermannsschlacht` eine immer weitere Verbreitung. ALBERTI berichtet 1894 allein von mehreren Aufführungen in Berlin; sie waren deutlich nationalistisch geprägt, doch schien das Stück zumeist unter Berücksichtigung des ,sittlichen Empfindens ‘ bearbeitet worden zu sein.

Es gab aber, wie die schon benannte Aufführung des Meiningensche Hoftheaters andeutet, im neunzehnten Jahrhundert zahlreiche Inszenierungen und Bewertungen, die ohne Einschränkung (bezüglich Form oder Aussage) positiv ausfielen: die also den ,Nationalismus' des Stückes teilten und die seine Ästhetik als gerechtfertigt und notwendig ansahen. Otto BRAHM schrieb beispielsweise 1884 in seiner KleistBiographie, die ,Hermannsschlacht ${ }^{\star}$ sei kein ,Bardengeheul ${ }^{\star}$ wie andere germanisierende Dichtungen, sondern wirklich die Verkörperung der Volksseele. Die positive Bewertung des Nationalismus wurde in der zweiten Hälfte des neunzehnten Jahrhunderts, noch mehr nach der Jahrhundertwende immer ausgeprägter; damit wurden auch die formalen und ästhetischen Strukturen des Stückes immer stärker akzeptiert. Dementsprechend wurde die ,Hermannsschlacht“ nun sogar zur Vorlage weiterer Bearbeitungen, die auf dieser Einheit von Inhalt und Form fußten, wie die Bardenchorvertonung von Hans Pfitzner; weitere Pläne deuten bereits die nationalsozialistische Rezeptions- und Aufführungspraxis an, etwa die Idee Maria GRUNEWALDS aus dem Jahr 1925, die ,Hermannsschlacht ${ }^{\star}$ als ,Weihespiel ${ }^{\star}$ darzubringen.

Gegen Ende des neunzehnten Jahrhunderts entwickelte sich zu den drei dargestellten Positionen aber auch die vierte, die ihre Faszination (gerade hinsichtlich Ästhetik, Form und dramatischer Durchgestaltung) nicht leugnete, das nationalistische Konzept Kleists aber ablehnte. Max Quarck schrieb 1902, mit dem für bürgerliche Begriffe ,maßlosen“ Hass gegen seine Feinde demonstriere Heinrich von Kleist gegen die bloße ,Kulissenarbeit‘ seiner ,Klassengenossen“: „Jedenfalls war Heinrich von 
Kleist der letzte, der mit dem deutschen Spießbürgertum sich ausgesöhnt hätte“ (QUARCK 1902: 949).

Daneben hatte aber auch nach wie vor die liberale Position Bestand. Wichtige Interpretationen finden sich in den Kleistbüchern Friedrich Gundolfs und Stefan Zweigs, die die ,Hermannsschlacht“ von einem eher individualistischen Standpunkt aus deuteten. Ihre Analysen wollten insbesondere die nationalistische Entwicklung Kleists erklären - Gundolf führte sie, psychologisierend, auf Kleists pathologischen Hass zurück (GuNDOLF 1924: 118); Stefan Zweig im darauffolgenden Jahr, ebenso psychologisierend, auf sexuelle Zwänge (ZwEIG 1925).

Wie bereits angedeutet, wurden aber bereits mit dem Erstarken der politischen Rechten am Ende der Weimarer Republik, vor allem aber in der Zeit des Nationalsozialismus nahezu ausschließlich Arbeiten publiziert, die die Anschauung teilten, sowohl den als nationalistisch empfundenen Charakter der ,Hermannsschlacht', als auch die ästhetische Struktur uneingeschränkt positiv zu bewerten und die, wie beispielsweise Georg HEMPEL 1930, eine ,,völkische Deutung" vertraten. Demzufolge hat sich auch das Theater während der nationalsozialistischen Herrschaft kräftig des Kleistschen Patriotismus bedient.

Ebenso zwangsläufig änderte sich nach dem zweiten Weltkrieg die Einschätzung diametral, gerade weil die ,Hermannsschlacht` ${ }^{`}$ ur Bestätigung nationalsozialistischer Ideologie herangezogen worden war. Rechtsextreme Positionen wurden deshalb nun nicht mehr (öffentlich) vertreten. Vertreter liberal-konservativer Traditionen hatten zunächst noch versucht, die ,Hermannsschlacht` wegen der (von ihnen immer noch geschätzten) künstlerisch-ästhetischen Qualitäten vor einer Verurteilung als nationalsozialistisches Wegbereiterstück zu retten. Aus diesem Grund wurde der formale Wert des Stückes gewürdigt, die als nationalistisch empfundene Aussage aber lediglich psychologisch erklärt und ihre politische Brisanz damit zumindest relativiert. Teilweise wurde gar dialektisch argumentiert, um (wie Heinz Ide) Kleists „Nationalismus' als Ausdruck einer im Grunde kosmopolitischen Gesinnung darzustellen: „Die Franzosen missfielen Kleist, weil er selbst der ,Franzose` zu sein meinte, der sie sein sollten, doch nicht zu sein vermöchten“ (IDE 1965).

Insgesamt wurde das Stück aber weitgehend gemieden; dies wird auch daran deutlich, dass wichtige Schaupielführer sowohl der Bundesrepublik Deutschland (beispielsweise HENSEL 1966), als auch der Deutschen Demokratischen Republik 
Giessen, H. W. - Medienanalytische Betrachtungen

(beispielsweise

BERGER/BÖTTCHER/HOFFMANN/NAUMANN

die

„Hermannsschlacht` kurz bei der Darstellung von Kleists Leben nennen, auf eine ausführliche Präsentation aber verzichten. Allerdings hatte es in der DDR in den fünfziger Jahren eine Inszenierungen gegeben: 1957 kam es im Harzer Bergtheater zu Thale zu einer Freilichtaufführung; allerdings erst, nachdem „,eine Anzahl führender Persönlichkeiten des kulturellen Lebens" nach ihrer Meinung darüber gefragt" worden waren; Siegfried STRELLER berichtet aber auch, dass dieser ,Versuch“ „seither ohne Nachfolge“" geblieben sei (1978: 695). Theoretisch beschäftigte sich die marxistische Literaturgeschichtsschreibung allerdings mit Kleists ,Hermannsschlacht" und entwickelte bereits in den frühen sechziger Jahren in Arbeiten von Ernst FISCHER (1961) und Hans MAYER (1962) den Ansatz beispielsweise von Georg Lukács weiter, mit dem dieser 1936 auf die nationalistische Interpretation und Vereinnahmung Heinrich von Kleists reagiert hatte: sowohl Kleists soziale Herkunft wie auch die soziale Rolle seines Publikums stelle den sozialen Nährboden für nationalistisches Gedankengut dar (LUKÁCS 1936: insbesondere 201ff).

In Westdeutschland wurde die Beschäftigung mit den Gründen, die Kleist zu diesem Stück veranlasst haben könnten, erst nach 1968 intensiviert. Jetzt wurde erneut die Frage diskutiert, „wieweit und in welcher Weise die Struktur des Werkes durch seine Tendenz bedingt ist" (ALlEMAnN 1981: 53). Dennoch hatten die Bühnen der Bundesrepublik das Stück gemieden: Claus Peymanns Inszenierung war mithin der erste Versuch einer Beantwortung dieser Frage; seine Verfilmung öffnete dieses Problem der Diskussion durch ein breites Publikum.

\section{2}

Heute ist die psychologisierend-erklärende Bewertung wohl herrschende Meinung (KITTLER 1987). Sie impliziert häufig einen rechtfertigenden Ansatz, der Folge grundsätzlicher Probleme mit der ,Hermannsschlacht“ ist. Wie die folgende Interpretation verdeutlichen wird, teilt Claus Peymann offensichtlich diese psychologisierende Sicht.

Häufig wird betont, dass Heinrich von Kleist in Distanz zur ihn umgebenden Gesellschaft gelebt habe. Dies ist beispielsweise die These von HоHOFF (1958) oder von BLÖCKERS (1960). Als Grund wird das Ich-Bewusstsein Kleists genannt, das aus seiner konsequenten und radikalen Beschäftigung mit existentiellen Fragen hergerührt 
Giessen, H. W. - Medienanalytische Betrachtungen

habe. Die Antworten Kleists auf die existentielle Problematik seien auf Unverständnis gestoßen beziehungsweise aus Furcht vor den Folgen verdrängt worden; diese Distanz habe Kleist jedoch seine Singularität nur noch bewusster empfinden lassen. Gleichzeitig habe Kleist die ,Sehnsucht' (SCHÄFER 1993) nach dem Übereinklang von Innenwelt und Außenwelt besessen. Es habe sich dabei um den Wunsch gehandelt, die persönliche Einsamkeit zu überwinden, ohne von der (die Einsamkeit unter Umständen ja erst hervorrufenden) Beschäftigung mit existentiellen Problemen - und seinen persönlichen Antworten darauf - Abstand nehmen zu müssen. Heinrich von Kleist habe in der allgemeinen nationalen Stimmung, die er offenbar teilte, eine Möglichkeit gesehen, die Übereinstimmung seines Tuns mit dem gesellschaftlichen Wollen zu erreichen (für viele: STRELLER 1978; ALLEMANN 1981). Beda Allemann charakterisiert den „Nationalismus Heinrich von Kleists“ als „den Versuch der Integration seines schriftstellerischen Tuns in die Forderungen der Zeit und der Gesellschaft“, die ,unter dem Zeichen eben des Nationalismus stand“ (AlLEMANN 1981: 47). Diese Bewertung aus dem Jahr 1981 scheint auch heute noch die herrschende Meinung der KleistForschung darzustellen.

Konservative Interpreten haben Kleists Nationalismus weniger sachlichpsychologisch als Allemann dargestellt (wo Kleist ja schon eine, wenn auch subjektiv von ihm wohl nicht empfundene, utilitaristische Tendenz unterstellt wurde). Ein Beispiel für diese Bewertung ist die populäre Schrift von Curt HOHOFF aus dem Jahr 1958, die Kleists Entwicklung noch auf das Empfinden einer „,heiligen“ Pflicht“ zurückführt:

In den Monaten des Winters 1808/09 glaubte Kleist seiner Bestimmung nah zu sein wie nie zuvor, da das, was ihm teuer war, der ganzen Nation teuer war - oder teuer hätte sein sollen. Zum ersten Mal fühlte er sich befreit aus dem Gefängnis seiner Seele (HOHOFF 1958: 104).

Der zweite Satz drückt dieselbe Einschätzung aus; sie erfolgt aber nicht individualistisch-psychologisierend, sondern aus der Sicht eines moralischen Wertesystems, in dem Nationalismus nicht grundsätzlich hinterfragt wird. Andererseits haben auch kritische Autoren die politische, nationale Absicht Kleists in der Regel nicht bestritten: so spricht Siegfried STRELLER deutlich von einem ,politische[n] Tendenzdrama“" (1978: 682). 
Giessen, H. W. - Medienanalytische Betrachtungen

Zumindest die persönlichen Hoffnungen, die sich Heinrich von Kleist bei der Abfassung der ,Hermannsschlacht“ (auch) gemacht hat, erfüllten sich nicht; das Werk stieß, wie beschrieben worden ist, zu seinen Lebzeiten überwiegend auf Ablehnung. Kleist blieb „unverstanden“ und zudem auch weiter stark ,vereinsamt“ (HoRN 1980: 112); die ,Sehnsucht" nach Aufhebung der Trennung von Innen- und Außenwelt wurde nicht aufgelöst. So hat die schlechte Aufnahme der ,Hermannsschlacht‘, wie auch des darauffolgenden ,Prinzen von Homburg', wohl einen nicht unbeachtlichen Anteil an Kleists Selbstmord, der ja nur zwei Jahre nach Vollendung der „Hermannsschlacht“ erfolgt ist.

Der psychologisierende Erklärungsansatz erlaubt es immerhin, politische Tendenz wie formale Gestaltung der ,Hermannsschlacht' nun ,von außen“ zu bewerten und einzuordnen. Insbesondere ermöglicht er es zum ersten Mal wieder (nach der antibürgerlichen, marxistisch inspirierten Episode, die hier am Beispiel Max Quarcks dargestellt worden ist), sich der formalen Faszination des Werks zu stellen (und sich ihr auszusetzen), ohne sich seine (politischen) Implikationen zu eigen machen zu müssen. Diesen Weg ist, wie gezeigt werden wird, Claus Peymann gegangen; darin liegt die historische Bedeutung seiner Interpretation.

\section{Die Interpretation von Claus Peymann}

\section{1}

Die beiden leitenden Prinzipien - politische Tendenz und künstlerische Struktur durchziehen die gesamte Rezeptionsgeschichte. Sie werden, je nach der Sicht des Beurteilenden und der historischen Situation, aus der seine Beurteilung erfolgt, in einem unterschiedlichen Verhältnis zueinander gesehen, wobei zwar Schwerpunkte gesetzt, aber keine zwangsläufigen Korrelationen gefunden werden können; alle vier möglichen Positionen sind - in historisch abhängiger, unterschiedlicher Intensität - bereits vertreten worden.

Umgekehrt sagt möglicherweise aber auch die Art und Weise der Beschäftigung mit der ,Hermannsschlacht“, die Herangehensweise an diese Prinzipien, auch etwas über die jeweils aktuelle historische Situation aus: Sie ist demnach ein Indikator für aktuelle, 
virulente Befindlichkeiten. Vor diesem Hintergrund ist die Beschäftigung mit Claus Peymanns Interpretation von besonderem Interesse.

Am 5. November 1982 hatte Peymanns Inszenierung der ,Hermannsschlacht' im Bochumer Schauspielhaus Premiere. Die Hauptrollen spielten Gert Voss, Kirsten Dene, Ulrich Pleitgen und Urs Hefti; das Bühnenbild wurde von Vincent Callara, die Kostüme von Ursula Renzenbrink gestaltet; die musikalische Einrichtung besorgte Heiner Goebbels. Die Inszenierung wurde als „radikale neue Deutung von Kleists „Hermannsschlacht““" (so C. Bernd SUCHER 1982: 12) bewertet (wobei anhand der hier herausgearbeiteten Kriterien zu untersuchen ist, ob sie dies tatsächlich ist); sie erhielt „am Ende der dreieinhalb Stunden [...] hingerissenen Beifall, lange währende Ovationen“ (HENSEL 1982: 25), und wurde in der Kritikerumfrage der Zeitschrift ,Theater heute“ zur „Aufführung des Jahres“ für die Saison 1982/83 gewählt. Zudem wurde sie, wie erwähnt, für die ZDF-Reihe ,Die aktuelle Inszenierung ‘ ausgewählt (und auf der Videoaufzeichnung dieser Verfilmung aus dem Jahr 1984 fußt auch die folgende Analyse).

\section{2}

Der Fernsehfilm „Heinrich von Kleist, ,Die Hermannsschlacht”, nach einer Aufführung aus dem Schauspielhaus Bochum“ wurde vom Regisseur der Bochumer Inszenierung selbst bearbeitet. Das ZDF verpflichtete auch jeweils einen der profiliertesten Kameramänner und Cutter Deutschlands: als Kamermann Thomas Mauch, als Cutter Thorsten Näter. (Dass die Bewertung Näters und Mauchs nicht subjektiv ist, sondern allgemein geteilt wird, belegt beispielsweise HEMBUS 1981: 296). Der Film entstand auf der Bühne des Bochumer Schauspielhauses; in jeder Szene ist der Bühnenhintergrund zu sehen. Der Fernsehfilm scheint eine handlungs- und zeitmäßig exakte Abfilmung der Inszenierung zu sein; auch spektakuläre Szenen, die die Kargheit, die das Bühnenbild nahezu die gesamte Inszenierung über charakterisiert, durchbrechen (wie die Zerstückelung Hallys, die Bärenszene, die Schlachtszene oder Hermanns ,Schattenspiel'; der Begriff ,Schattenspiel‘ wurde von Benjamin HENRICHS (1982: 45) übernommen und wird später erläutert werden), entstammen der Originalinszenierung, wie ein Vergleich der Verfilmung mit den Kritiken zur Premiere in Bochum ergab, die diese Szenen ebenfalls besonders beschreiben: Demnach entsprechen die Szenen im Fernsehfilm denen der Inszenierung (vergleiche SUCHER 1982, HENSEL 1982, 
HeNRICHS 1982 oder auch Peymanns Äußerungen in PEYMANN 1984: insbesondere 3). Der Fernsehfilm ist damit an die Vorgaben der Bühneninszenierung zumindest gebunden, da sie das gesamte ,Material` des Films liefert, der Film also keine ,Ereignisse‘ zeigt, die nicht auch in Bochum zu sehen gewesen wären.

Die Aufführung wird durch bühnentechnische Notwendigkeiten begrenzt; dieser Begrenzung unterliegt demzufolge auch der Fernsehfilm, was bedeutsam ist, da es sich um ein anderes Medium handelt, dessen tatsächliche Möglichkeiten dadurch erheblich eingeschränkt werden. Der Zuschauer des Fernsehfilms ist sich mithin jederzeit bewusst, dass es sich um eine abgefilmte Bühneninszenierung handelt.

Der Fernsehfilm erfüllt damit die Funktion der Dokumentation der Bochumer Inszenierung zumindest in Bezug auf die äußere Handlung. Die Bühnenaufführung eines Theaterstücks ist jedoch grundsätzlich auf die Reaktion eines anwesenden Publikums hin konzipiert; dies unterscheidet sie in der Regel von einer Verfilmung. Auch die Inszenierung der ,Hermannsschlacht‘ im Bochumer Schauspielhaus scheint (in sogar hohem Maße) auf die Reaktion des Publikums zugeschnitten gewesen zu sein: Georg Hensel betont beispielsweise in Bezug auf Peymanns Konzept, „[...] wo er Gelächter herausschlagen kann, da schlägt er unerbittlich zu“ (HENSEL 1982: 25). Dass solche Reaktionen von Peymann auch tatsächlich einkalkuliert worden waren, hat er selbst betont: „Ich glaube, dass Kleist auch sehr für das Lachen war und dass er auch das Lachen des Schreckens kennt, das Lachen des Erschreckens und des Erkennens und des Verzweifelns. In diesem Sinne habe ich nichts dagegen, wenn die Leute sich in unserer Aufführung amüsieren“ (PEYMANN 1984). Dies scheint auch häufig geschehen zu sein; die Rezensenten der Premiere berichten von vielen solcher Momente, etwa „wenn Hermann über das Recht des Gefangenen höhnisch lacht und das Publikum mit ihm“ (HENSEL 1982: 25), oder in Hinblick auf das bereits erwähnte ,Schattenspiel`, die Projektion von Hermanns Schatten an die Bühnenwand in Form eines riesigen Hermannsdenkmals: „Natürlich ein Riesengelächter“ (HENRICHS 1982: 45), „ein Anlaß zu amüsiertem Gelächter“ (HENSEL 1982: 25). Die Selbstverständlichkeit, mit der Benjamin Henrichs in Bezug auf das ,Riesengelächter` das Wort ,natürlich“ verwendet, lässt erkennen, als welch wesentlicher Bestandteil der Inszenierung die Publikumsreaktionen einkalkuliert worden sein müssen.

Der Fernsehfilm wurde allerdings ohne Publikum produziert; damit entfallen (natürlich) auch die Zuschauerreaktionen. Sie ließen sich vom Fernsehzuschauer 
Giessen, H. W. - Medienanalytische Betrachtungen

vermutlich auch nicht nachvollziehen: Vor allem ist die Wirkung solcher Szenen (wie der Genese eines monumentalen Hermannsdenkmals) grundsätzlich sehr anders, wenn sie auf einem kleinen Bildschirm beobachtet wird (GIESSEN 2004: 129). Die Aussparung des originalen Theaterpublikums bei der Fernsehverfilmung ist also ein Indiz dafür, dass sich Peymann der Charakteristika des Mediums bewusst ist und sie auch gezielt einsetzt.

Dies zeigt sich auch an anderen Stellen. So nutzt Peymann beispielsweise die Kamera, um Abstraktes visuell zu verdeutlichen: Im ersten Auftritt des vierten Aktes erklärt Luitgar dem Suebenfürsten Marbod den Schlachtplan Hermanns. In der Verfilmung zeichnet Luitgar dabei die Schlachtskizze mit weißer Kreide auf den schwarzen Boden der Bühne; dabei schaut ihm die Kamera über die Schulter und vermittelt dadurch dem Zuschauer ebenfalls die (visuelle) Kenntnis des Schlachtplans.

Der Fernsehfilm hat demnach nicht allein die Aufgabe, die Bochumer Inszenierung zu dokumentieren; im Gegenteil verändert sie die Originalinszenierung (durch die Art der Kamerabenutzung, durch das Fehlen des Publikums) so sehr, dass von einer reinen Abfilmung nicht mehr gesprochen werden kann. Andererseits deutet die Nutzung der Inszenierung als ,Material“ (durch denselben Regisseur) darauf hin, dass das inhaltliche Konzept von Theaterinszenierung und Fernsehfilm identisch ist; indem es (mediengerecht) weitervermittelt wird, hat der Film gerade einen jenseits des Äußerlichen liegenden dokumentarischen Charakter. Offensichtlich liegt darin das Ziel Peymanns-nicht in der, reinen` (und damit äußerlichen) Dokumentation.

Dies soll noch einmal verdeutlicht werden. Die Unterschiede sind in den Gesetzmäßigkeiten des Mediums Film zu suchen (sie drücken sich in dem Untertitel des Films aus: „nach einer Aufführung aus dem Schauspielhaus Bochum“). Fraglich könnte dann aber gerade sein, warum Peymann über zahlreiche Entscheidungen bei der Filmfassung nicht freier verfügt hat - möglicherweise hätte er seine Intentionen noch medien- und damit publikumsgerechter und wirksamer ausdrücken können. So hätte er beispielsweise für die Verfilmung die Bühne des Bochumer Schauspielhauses verlassen und in einer realen Landschaft drehen können, etwa im Teutoburger Wald selbst - Peter Stein hat eine solche Vorgehensweise ja beispielsweise in seiner Verfilmung von Maxim Gorkijs „Sommergästen“ getan, die auf seine Inszenierung an der Berliner Schaubühne (damals noch: am Halleschen Ufer) zurückging. Steins Bühnenfassung unterscheidet sich allerdings auf vielerlei Art und Weise von Peymanns Kleist- 
Giessen, H. W. - Medienanalytische Betrachtungen

Inszenierung, so etwa durch die Wahl der Kostüme, die einheitlich sind und aus der Zeit stammen, in der Gorkij das Stück geschrieben hat und in der es auch spielt, während Peymann jede Epocheneinheitlichkeit bewusst vermieden und beispielsweise einen germanischen Flügelhelm neben einen an britische Kolonialisten mahnenden Tropenhelm oder eine (noch heute übliche) Baskenmütze gesetzt hat. Über die möglichen Intentionen Peymanns später mehr - auf jeden Fall wird dadurch der Effekt einer gewissen Verfremdung erreicht; dass diese beabsichtigt ist, macht die Inszenierung mit ihrer grundsätzlichen Kargheit, Schwärze und Leere der Bühne deutlich; dies wird aber auch in anderen, über diese Kargheit hinausgehenden Szenen vorgeführt, etwa bei der Zerstückelung Hallys; etwa in der Bärenszene, inszeniert als kitschiges Gruselstück; etwa durch die irreal-riesige Erstarrung Hermanns zum Hermanns-Denkmal. Mit diesem Ziel der Verfremdung, das die Bühneninszenierung geprägt hat, kann auch die Entscheidung Peymanns erklärt werden, nicht etwa im realen Teutoburger Wald zu drehen. Auch der Entschluss, häufig keine Änderungen bei der Verfilmung vorzunehmen, erscheint nachvollziehbar und begründet.

Gerade diese Tatsache zwingt dazu, den Fernsehfilm als eigenständiges künstlerisches Werk zu bewerten. Es ist insoweit gelungen, als es ein konsistentes, autarkes Gebilde darstellt; das heißt, dass es auch allein, ohne Kenntnisse etwa bühnentechnischer Notwendigkeiten rezipiert werden kann. Es benutzt zwar ausschließlich das Bildmaterial, das ihm die Bochumer Aufführung zur Verfügung gestellt hat, ist aber keine Abfilmung (die dann ,nur' dokumentarischen Wert hätte). Es benutzt die Inszenierung, um das selbe Konzept in einem anderen Medium zu vermitteln. Dieses Konzept soll im folgenden analysiert und seine Umsetzung bewertet werden.

Die Analyse hat damit die erste existente eigenständige ,Hermannsschlacht'Verfilmung zum Gegenstand. Die Verfilmung wirft ein neues Licht auf die genannten, rezeptionsgeschichtlich entscheidenden Prinzipien. Von daher ist sie für die Bewertung der ,Hermannsschlacht“ wie auch für die Rezeptionsgeschichte Kleists von besonderer historischer Bedeutung.

\section{3}

Claus Peymanns Inszenierung der ,Hermannsschlacht“ zeichnet sich vor allem durch ihren Respekt vor Kleists Text aus. Als Beispiel für die Art und Weise, wie Peymann 
Giessen, H. W. - Medienanalytische Betrachtungen

beim Streichen vorgegangen ist, soll nun der erste Auftritt des ersten Aktes dienen. Die Auslassungen Peymanns sind in eckige Klammern gesetzt:

Wolf:

Es ist umsonst, [Thuskar,] wir sind verloren!

Rom[, dieser Riese, der, das Mittelmeer beschreitend,

Gleich dem Koloß von Rhodos, trotzig,

Den Fuß auf Ost und Westen setzet,

Des Parthers mut'gen Nacken hier,

Und dort den tapfern Gallier niedertretend:

Er] wirft auch jetzt uns Deutsche in den Staub.

Gueltar[, der Nervier,] und Fust[, der Fürst der Cimbern,]

Erlagen dem Augustus schon;

Holm [auch, der Friese,] wehrt sich nur noch sterbend;

Aristan hat[, der Ubier,

Der ungroßmütigste von allen deutschen Fürsten,]

In Varus' Arme treulos sich geworfen;

Und Hermann, der Cherusker, endlich,

zu dem wir, als dem letzten Pfeiler, uns[,

Im allgemeinen Sturz Germaniens,] geflüchtet,

Ihr seht es, Freunde, wie er uns verhöhnt:

Statt die Legionen mutig aufzusuchen,

In seine Forsten spielend führt er uns,

und läßt den Hirsch uns und den Ur besiegen.

Thuiskomar:

Er muß hier diese Briefe lesen!

- Ich bitt' euch, meine Freunde, wanket nicht,

Bis die Verräterei des Varus ihm eröffnet.

Ein förmlicher Vertrag ward jüngst

Geschlossen zwischen mir und ihm:

Wenn ich dem Fürsten mich der Friesen nicht verbände,

So solle dem August mein Erbland heilig sein;

Und hier, seht diesen Brief, ihr Herrn,

Mein Erbland ist von Römern überflutet.

Der Krieg, so schreibt der falsche Schelm,

[In welchem er mit Holm, dem Friesen, liege,]

Erfordere, daß ihm Sicambrien sich öffne[:

Und meine Freundschaft zu Augustus lass' ihn hoffen,

Ich werd' ihm diesen dreisten Schritt,

Den Not ihm dringend abgepreßt, verzeihn].

Laßt Hermann, wenn er kömmt, den Gaunerstreich uns melden[:

So kommt gewiß, Freund Dagobert, 
Giessen, H. W. - Medienanalytische Betrachtungen

Freund Selgar, noch der Bund zustande,

Um dessenthalb wir hier bei ihm versammelt sind].

Dabobert:

[Freund Thuiskomar!] Ob ich dem Bündnis mich, Das diese Fremdlinge aus Deutschland soll verjagen, Anschließen werd', ob nicht: darüber, weißt du, Entscheidet hier ein Wort aus Selgars Munde!

[Augustus trägt, Roms Kaiser, mir,

Wenn ich mich seiner Sache will vermählen,

Das ganze, jüngst dem Ariovist entrißne,

Reich der Narisker an -

Nichts! Nichts! Was fahrt ihr auf? Ich will es nicht!

Dem Vaterlande bleib' ich treu,

Ich schlag' es aus, ich bin bereits dazu.

Doch] der hier[, Selgar,] soll [, der Fürst der Brukterer,]

Den Strich mir, der mein Eigentum,

An dem Gestad“ der Lippe überlassen;

Wir lagen längst im Streit darum.

Und wenn er mir Gerechtigkeit verweigert,

[Selbst jetzt noch, da er meine Großmut braucht,]

So werd" ich mich in euren Krieg nicht mischen.

\section{Selgar:}

Dein Eigentum! Sieh da! Mit welchem Rechte

Nennst du, was mir verpfändet, dein[,

Bevor das Pfand, das Horst, mein Ahnherr, zahlte,

An seinen Enkel du zurückgezahlt?

Ist jetzt der würd'ge Augenblick,

zur Sprache solche Zwistigkeit zu bringen?]

Eh' ich[, Unedelmüt'gen,] dir

Den Strich am Lippgestande überlasse,

Eh' will an Augusts Heere ich

Mein ganzes Reich, mit Haus und Hof, verlieren!

[Thuiskomar:

O meine Freunde!

Ein Fürst:

Selgar! Dagobert!

Ein Cherusker:

Hermann, der Fürst, kommt! 
Thuiskomar:

Laßt den Strich, ich bitt` euch

Ruhn, an der Lippe, bis entschieden ist,

Wem das gesamte Reich Germaniens gehört!

Wolf:

Da hast du recht! Es bricht der Wolf, o Deutschland, in deine Hürde ein, und deine Hirten streiten

Um eine Handvoll Wolle sich.]

Das Ausmaß der Kürzungen in diesem Auftritt ist in etwa repräsentativ für Peymanns Vorgehensweise: Er hat stellenweise konsequent, doch nie übermäßig oder verfälschend gestrichen.

Nur ein einziges Mal stellt Peymann Szenen um - allerdings an einer wichtigen Stelle: im dritten Auftritt des vierten Aktes. Er beginnt (wie im Originaltext, allerdings teilweise gekürzt) mit dem Zwiegespräch zwischen Hermann und Eginhardt, das vor dem für die Inszenierung charakteristischen schwarzen Hintergrund stattfindet. Es bricht jedoch mitten im dritten Auftritt mit Hermanns Ausruf „Horch“! Still!“ ab; und es folgt die als „fernöstliches Maskenspiel“ stilisierte Szene, in der die Zerstückelung Hallys vorbereitet wird (und schließlich, später, auch erfolgt); also mit dem vierten Auftritt. Mit dem Aufschrei Teutholds „Gott im Himmel!/ Hally, mein Einziges, was widerfuhr dir?" bricht wiederum das Maskenspiel ab; und Peymann setzt den dritten Auftritt bis zum Ende fort. Erst dann wird das Maskenspiel weitergeführt, zu dem später, entsprechend der Textvorlage, auch Hermann und Eginhardt stoßen. Auch dieser Eingriff Peymanns ist eher behutsam; er bedeutet tatsächlich eine leichte Spannungssteigerung in Form eines retardierenden Moments, ohne den Charakter der Szene zu verändern.

Es findet sich auch nur eine einzige Stelle, an der Peymann Personen auslässt (und ihren Text anderen übergibt): im ersten und zweiten Auftritt des vierten Aktes, wo Hermanns Kriegsplan von Luitgar dem Marbod unterbreitet wird. In der Textvorlage ist Marbod zunächst skeptisch und fragt den misstrauischen Attarin um Rat; beide prüfen dann Hermanns Söhne, die dieser dem Marbod als Geißeln gegeben hatte, ob es die echten Kinder Hermanns seien. Dieses Fragespiel ist für den Leser (und Zuschauer), der 
Giessen, H. W. - Medienanalytische Betrachtungen

den wahren Sachverhalt ja bereits kennt, ohne neuen Erkenntnisgewinn; auch dramaturgisch ist es nicht notwendig: (wohl) deshalb hat Peymann es ausgelassen weder Hermanns Söhne noch Attarin erscheinen in der Inszenierung; der Schlachtplan wird dem Marbod von Luitgar direkt übermittelt. Marbod übernimmt hier auch den Originaltext Attarins (sofern er nicht wegfällt); an einer Stelle übernimmt Luitgar (sogar) den Text, den Kleist Marbod zugedacht hatte: In der Vorlage besänftigt Marbod Attarins Zweifel; bei Peymann äußert Marbod selbst die Bedenken, und Luitgar stellt sich ihnen mit Marbods Originaltext entgegen.

Insgesamt war der Regisseur aber mit Kürzungen oder Veränderungen der Textvorlage zurückhaltend. In stärkerem Ausmaß hat er noch bei der Schluss-Szene gestrichen, wo die Diskussion über die Frage, wer Herrscher über die Deutschen werden solle, komplett ausgelassen worden ist. Es gibt aber auch Szenen, die mit derselben Berechtigung hätten gekürzt werden können, aber belassen wurden - so dass eher der Eindruck entsteht, Peymann wolle mit seiner Inszenierung Kleists Wortbilder zelebrieren: die Bescheidenheit eines Regisseurs vor einem bewunderten Text. So könnte auch die Tatsache interpretiert werden, dass die Bühne in Bochum fast durchgängig leer blieb, das Bühnenhaus mit schwarzen Wänden und Vorhängen bedeckt war: Dieser Entscheidung lag demnach der Wunsch zugrunde, Kleists Text für sich alleine wirken zu lassen, möglichst ohne ablenkende Einflüsse. Diese Interpretation wird durch Eigenbewertungen Peymanns gedeckt. Er hat beispielsweise Skrupel hinsichtlich der wenigen Szenen geäußert, die diese Kargheit durchbrechen: „Das sind für mich Bilder, bei denen wir eigentlich gar nicht die Mittel hatten, wo wir poetisieren mussten; obwohl es als ein großes Verdienst der Aufführung gewertet wird, ist es eher eine Schwäche“ (PEYMANN 1984: 3). Die Zurückhaltung des Regisseurs wurde auch von Kritikern beobachtet: „Noch nie hat Claus Peymann eine Inszenierung so ruhig entwickelt, ganz aus dem Innern des Textes. [...] Noch nie hat er so ,erwachsen“ inszeniert, seine Kindeslust an den schönen Spielen des Theaters bezähmt“" (HENRICHS 1982: 45). Peymanns Absicht scheint es also (zumindest auch) gewesen zu sein, den Text Kleists möglichst wenig durch Eingriffe $\mathrm{zu}$ stören oder $\mathrm{zu}$ überlagern. Notwendigerweise gilt dies dann auch für den Fernsehfilm; darin muss ein weiterer Grund beispielsweise für die Entscheidung gesehen werden, den Fernsehfilm auf der leeren Bühne (und nicht etwa in einer realen Landschaft) zu drehen. 
Giessen, H. W. - Medienanalytische Betrachtungen

3.4

Problematisch wäre (insbesondere vor dem Hintergrund der schwierigen Rezeptionsgeschichte dieses Werkes) gewesen, wenn diese dienende Absicht das einzige Ziel Peymanns gewesen sei. Tatsächlich hat sich ein entsprechender Eindruck lange Zeit gehalten, wie beispielsweise C. Bernd Sucher verdeutlicht hat: ,[...] - dass er [Claus Peymann] dieses Stück ausgegraben hatte, blieb überraschend, seltsam. Noch in der Pause, da waren die ersten sieben Szenen des vierten Aktes bereits gespielt, war unklar, wie Peymann seine Gratwanderung fortsetzen würde. Irgendetwas mußte er unternehmen, um Hermann, diesem kühlen Kopf mit Führereigenschaften, den Nimbus des Retters zu nehmen“(SUCHER 1982: 12). Es gelang dem Regisseur dann doch, eine eigene Deutung der ,Hermannsschlacht` zu Ausdruck zu bringen (Suchers nächster Satz lautet denn auch: „Und es geschah etwas.“) - dennoch muss die Frage diskutiert werden, ob ein Text, der in einem solchen Ausmaß Unmenschliches ausdrückt, heute noch so respektvoll behandelt werden darf, nachdem ja bekannt ist, was die Folgen dieses Fremdenhasses sein können - beziehungsweise: was dieser Respekt im Jahr 1982 für die gesellschaftliche Entwicklung indiziert. Die Interpretation Peymanns stellt vor diesem Hintergrund eine wichtige Quelle dar, um Änderungen des ,Zeitgeistes` zu erkennen und zu bewerten.

\section{5}

Die Rezensenten der Premiere erklären das Konzept Peymanns von der Schluss-Szene aus. C. Bernd SUCHER (1982: 12):

Und es geschah etwas. Peymann stellt Gert Voss, den Bochumer Hermann, in der Schlußszene ganz allein auf die große leere Bühne. Jubel, Gewehrsalven, Musikdröhnen, und Hermanns Schatten, das lebendige Denkmal, wächst an der Bühnenrückwand, je weiter sich der Fürst von seinem Volk entfernt. Dann reißt sich Voss den Wikingerhelm vom Kopf, ärgerlich, enttäuscht. Darunter trägt er noch immer die Che-Guevara-Mütze. Der Revolutionär, der listig-subversive, der handelt, während die anderen reden und lamentieren, hat gesiegt. Aber er weigert sich, als Kriegsheld gefeiert zu werden, weil er weiß, daß er keinen Schritt vorangekommen ist auf dem Weg, die Freiheit zu retten.

Benjamin HENRICHS (1982: 45):

Vor dem Finale [...] noch ein Schattenspiel. Hermann, der Sieger, von einem Scheinwerfer illuminiert. An der Bühnenwand sein ins Riesenhafte wachsender Schatten: das Hermannsdenkmal. Natürlich ein Riesengelächter. 
Es ist gut, daß Peymann seine Inszenierung nicht mit diesem Licht- und Knalleffekt, mit dieser kritischen Platzpatrone aufhören läßt.

Sondern ganz anders: Die Bühne ist leer, das Bühnenhaus offen, die schwarzen Wände heruntergerissen. Hermann und Thusnelda, auf der weiten Bühne allein. Plötzlich erinnern die beiden an ein anderes großes Theaterpaar - an Bernhard Minetti und Edith Heerdegen, die im selben Theater Thomas Bernhards ,Weltverbesserer" spielten. Ein Weltverbesserer ist auch Hermann der Cherusker - getreu Bernhards Devise, daß die Welt nur verbessern kann, wer sie vernichtet.

Das ist das Ende. Die Römer sind ausgerottet. Deutschland ist gerettet. Die Welt ist leer.

Von dieser Schluss-Szene aus rückwirkend betrachtet, haben alle anderen wichtigen Elemente der Inszenierung - wie die kahle Schwärze des Bühnenhintergrunds oder die Kostüme - nur den Zweck, die Zeitlosigkeit und damit Abstraktionsfähigkeit dieses eigentlich für eine sehr konkrete politische Situation geschriebenen vaterländischen Schauspiels zu verdeutlichen; damit (auch) dem (negativen!) Interpretationskonzept dienend, das SUCHER (1982: 12) mit „Rettung? - Warten auf den Untergang“ umschrieben hat.

Zudem entsteht durch die genannten Inszenierungselemente eine symbolische Ebene (die bemerkenswerterweise von den Rezensenten zwar gesehen, aber nicht in ihrer Funktion gewürdigt wurde). So dient das Bühnenbild tatsächlich dem Abstraktionsprinzip - durch seine leere Schwärze, die keine Möglichkeit einer historischen Einordnung bietet; auch die Requisiten sind epochengeschichtlich und stilistisch uncharakterisierbar, wie der Thron Hermanns, ein lediglich in ein rotes Tuch eingeschlagener Stuhl; die Kostüme sind eine Mischung aus Gegenwartskleidern (die quantitativ wohl dominieren und damit erneut die Distanz zum ,klassischen Stoff demonstrieren), Kleidung aus der Entstehungszeit des Werks, der Zeit Kleists (Uniformrelikte wie Jacken oder Hosen), sowie Fragmente von Kleidungsstücken, die (klischeehaft) auf die Zeit der historischen Hermannsschlacht verweisen sollen (sie sind besonders auffällig, allerdings quantitativ schwächer vertreten: beispielsweise eine Flügelhelm, ein Kriegshelm mit Hörnern, Waffenteile); dazu kommen Kleidungsstücke, die auf imperialistische beziehungsweise kolonialistische Perioden verweisen (so britische Tropenhelme); schließlich sind auch die musikalischen Einsprengsel als kurze Zitate (Marschmusik, hymnenartige Musik) konzipiert, die auf überzeitliche Motive verweisen sollen.

Diese Zitate weisen auf eine weitere Interpretationsebene: Denn es handelt sich, über die gesamte Inszenierung hinweg, um zwar zeitlich durcheinandergehende, stets 
ungenaue und teilweise nicht einzuordnende, so doch anthropologisch sehr konkrete Symbole. Insgesamt haben sie so die Wirkung von Metaphern. Dies soll kurz am Beispiel des römischen Feldherrn Varus verdeutlicht werden: Er trägt einen Tropenhelm, der an die Kopfbedeckung britischer Kolonialoffiziere erinnert. Damit werden Kolonialismus und Imperialismus als die das britische Weltreich (zumindest aus der Sicht der heute wohl herrschenden Meinung) prägenden und leitenden Prinzipien auf Varus übertragen und implizit den Römern unterstellt und vorgeworfen. Die „Hermannsschlacht“ ist so zwar kein reales Ereignis mehr, sie wird aber (unter anderem) als Parabel auf den Kolonialismus genutzt. Damit kann das Stück auf alle historischen Situationen angewandt werden, die von ähnlichen Motiven geprägt sind. C. Bernd SUCHER deutet die Implikationen dieses Inszenierungsmerkmals nur an, wenn er schreibt (1982: 12): „Nichts ist in dieser Inszenierung übrig von Kleists Propaganda von ,Deutschlands großer Sache‘. Mit den Römern sind nicht mehr die Franzosen, mit den Cheruskern nicht die Preußen mehr gemeint, wenngleich auch in dieser Fassung [...] hier und dort die Anspielungen noch immer zu hören sind.“

Georg Hensels Differenzierung zwischen Hermann als Che Guevara und als Asterix kommt den Peymannschen Funktionsimplikationen bereits näher. Das Beispiel der Römer soll die Peymannsche Vorgehensweise weiter verdeutlichen: denn gerade die differenzierende, sich häufig widersprechende Symbolik, die gezielt negative, in bewusstem Gegensatz zur inhaltlichen Aussage des Stückes stehende Momente einsetzt, wurde von den Rezensenten der Premiere nicht herausgearbeitet. Die Römer sind grundsätzlich weiß gekleidet, die Germanen schwarz: Dies ist die Umkehrung der Farbenfolge, die normalerweise in Trivialfilmen zur Charakterisierung der Personen benutzt wird (dort sind die Guten immer weiß, die Bösen immer schwarz gekleidet). Für Kleist sind die Germanen ,gut` und die Römer ,schlecht' (dies ist ja die Grundaussage der ,Hermannsschlacht'); indem Peymann die Farbsymbolik umkehrt, distanziert er sich (doch!) von Kleist. Er verweist auf eine Ebene außerhalb des Stückes, in der diese ,Schwarz-Weiß-Malerei' unzutreffend ist. Die Aussage des Stückes wird durch die symbolische Farbumkehrung relativiert, gebrochen.

Es gibt weitere Beispiele für die Peymannsche Methode der umgekehrten, negativen Symbolik (- erneut von keinem Kritiker erwähnt). Kleist geht es ja darum, die Römer als hassenswerte Eindringlinge darzustellen, während sich die Germanen in einem nationalen Befreiungskampf befinden. Die Kampfhandlungen haben also keine 
(moralische) Legitimation, was die Römer betrifft; dagegen führen die Germanen einen ,gerechten Krieg' (der deshalb wiederum auch manch unmoralisches Verhalten legitimiert). Peymann relativiert diese Darstellung, in dem er da, wo die Römer brutal sind, das Geschehen auf eine imaginäre Sphäre enthebt; die Grausamkeiten der Germanen werden dagegen überdeutlich dargestellt. Nie sieht man die Römer Gewalttaten begehen: Als das Römerheer plündernd durch Cheruska nach Teutoburg zieht, wird auf die schwarze Bühnenwand lediglich ferner Feuerschein projiziert; das vergewaltigte Mädchen Hally, Opfer der Römer, taucht nur als ,Maske“ auf; die Schlacht selbst wird entsprechend der zwei Zeilen „Zerschellt ward nun das ganze Römerheer,/ Gleich einem Schiff, gewiegt in Klippen“ als grotesk hin- und herschwankendes, mit Musik unterlegtes Ballett, nicht als Kampf inszeniert (allerdings entfällt bei Peymanns Inszenierung der Text mit Ausnahme der genannten beiden Zeilen „Zerschellt ward nun das ganze Römerheer,/ Gleich einem Schiff, gewiegt in Klippen“, die nun gesungen werden). Die Aggressivität der Germanen wird dagegen mit viel Blut dargestellt: Dies beginnt bereits in den Anfangsszenen, als ein gerade erlegter Auerochse auf die Bühne geschleppt wird, ,die Pfeile stecken noch in seinem Körper, plötzlich stürzt Blut aus seinem Maul - beschmutzt [... die] leere Bühne“" (SUCHER 1982: 12); das setzt sich fort in der Bärenszene, in der tatsächlich ein Bär („ein[...] Schauspieler im schwarzen Bärenkostüm“, SUCHER 1982; 12) auf der Bühne seine Krallen in Ventidius bohrt; und das endet damit, dass Varus brutal abgeschlachtet wird: „Wenn sie [die ,germanischen Guerrilleros'] dem Varus die Hose herunterzerren und ihn abstechen wie ein Stück Vieh, suhlen sie sich in einem sexuellen Blutrausch.“ (HENSEL 1982: 25)

Die beiden Szenen, in denen der Auerochse und Varus getötet werden, sind von Peymann offenbar mit Absicht als eine Art Rahmen konzipiert worden: Gleich zu Beginn bringen die Germanen - ohne sichtbare Gefühlsregungen, mithin ohne Respekt vor dem Leben - das Tier um, und es verendet stark blutend; genauso stirbt vor dem Finale Varus, wörtlich: „Als wär' ich ein gefleckter Hirsch,/ Der, mit zwölf Enden, durch die Forsten bricht! -“; wie Georg HENSEL ja betont hat (1982: 25), stechen ihn die Germanen „wie ein Stück Vieh“ ab. Die Feinde sind für die Germanen offenbar keine Menschen mehr, sie werden wie Tiere behandelt; gleichzeitig deutet das rohe ,Abschlachten“ der Feinde aber auch an, dass sich die Germanen selbst brutal, wie Tiere, verhalten: Der Bär, der Ventidius zerfleischt, ist gleichzeitig Teil der 
Persönlichkeit Thusneldas; als Varus umgebracht wird, „suhlen sie [die Germanen] sich in einem sexuellen Blutrausch“ (HENSEL 1982: 25) - sie suhlen sich, wie wilde Tiere. Mit den Extremszenen des Rahmens werden die Motive, die (nach Peymanns Interpretation) die Germanen leiten, präsentiert: eine auf das Absolute zielende Grausamkeit, die gleichzeitig immer eine sexuelle Komponente hat.

Sehr aussagekräftig ist in diesem Kontext die Bärenszene, in der das Tier (anstelle von Thusnelda) den (offensichtlich noch immer) geliebten Mann, von dem aber klar geworden ist, dass er umgekehrt nicht verliebt ist, vielmehr ihre Liebe nur ausgenutzt hat, zerfleischt: durch das Zerfleischen kann er der Frau doch noch ganz gehören. Die Liebe ist demnach absolut und kann nur absolut empfunden werden; sie ist Ausdruck einer Geisteshaltung, die auf absoluten Werten besteht. Dies impliziert die totale Unterwerfung (hier: unter die Liebe Thusneldas). Ist die absolute Form nicht möglich, bleibt nur noch der Tod, das letzte Absolute. Dies ist einerseits eine Überhöhung (hier: der Liebe) ins Absolute, andererseits (und gleichzeitig) eine Reduktion: auf Selbstpreisgabe und Unterwürfigkeit. Mit dem Begriff der Liebe ist demnach zwangsläufig die Machtfrage gekoppelt, die hier vor allem physisch dargestellt und ausgelebt wird: sexuell und brutal.

Die Koppelung ist deshalb reziprok. Dies wird beispielsweise nach der Ermordung des Varus deutlich: Nachdem ihn die Germanenfürsten Fust und Gueltar getötet haben, nehmen sie ihn ganz in Besitz, indem sie sein Blut in ihren eigenen Gesichtern verreiben; dann küssen sie sich.

Wie eng Selbstaufgabe (beziehungsweise Macht) und Sexualität zusammenhängen, zeigt sich noch einmal im selben Auftritt, als Fust und Gueltar vor Hermann in Unterwürfigkeitspose knien. Hermann ist verwundet und blutet stark (die Wunde wurde von Gueltar selbst verursacht); aus ihrer Unterwürfigkeit heraus bedrängen beide Fürsten den Hermann sexuell (Gueltar: „Komm her, soll ich das Blut dir saugen?“ - Fust: „Mir laß - mir, mir!“). Die Verbindung zwischen Sexualität und Brutalität einerseits sowie Macht und Selbstaufgabe andererseits besteht, wie der Text beweist, bereits bei Kleist selbst; Peymann hat sie jedoch explizit herausgearbeitet und sie in den Mittelpunkt seiner Inszenierung gestellt. Sie verweist auf einen tiefenpsychologischen Zusammenhang, der gerade für den faschistischen beziehungsweise nationalsozialistischen Führerkult bestimmend war, wie Adorno 
Giessen, H. W. - Medienanalytische Betrachtungen

gezeigt hat (ADORNO 1971: 34ff). In der Inszenierung erscheint Hermann in diesem Moment als mystisch überhöhter Führer, vor dem Gueltar und Fust in die Knie sinken.

Die Filmanalyse verdeutlicht den Interpretationsansatz von Claus Peymann. In der Regel bestimmen totale, teilweise auch halbtotale und amerikanische Einstellungen die Verfilmung, so dass die Bühne immer zu sehen ist und die Personen nie von ihrer Umgebung losgelöst erscheinen. Dadurch entsteht eine gewisse Distanz zu ihnen, da man sich visuell nie ganz auf sie einlassen muss. Die Einstellungen sind zumeist relativ lang; nie verliert der Zuschauer den Überblick. Dies ändert sich nur in einzelnen Szenen - so, wenn Fust und Gueltar ihre Hände über Varus' blutverschmierte Brust tasten lassen, sich das Blut in ihre Gesichter reiben und sich dann küssen. Nicht beim Kampf selbst, sondern erst dann, wenn die Protagonisten sozusagen ihr Innerstes zu erkennen geben und so die Erklärung der ,Hermannsschlacht' versucht wird, ist der Zuschauer unmittelbar dabei und muss sich dem von Peymann herausgearbeiteten Motiv (Brutalität, verbunden mit Sexualität) direkt stellen; er kann (auf dem Bildschirm) nicht mehr ausweichen.

Im Finale zeigt Peymann dann die politischen Folgen dieses Zusammenhangs: Hermann, der Einzelne, wird (durch das Schattenspiel) zum gigantischen Denkmal, das allein bühnenbestimmend ist. Hymnenartige Musik überhöht das Bild noch mehr. Die Kamera bleibt bei ihrer unmittelbaren Darstellung; gleichzeitig wird die Kameraposition immer tiefer, so dass der Zuschauer, ähnlich wie Fust und Gueltar, klein und unterwürfig aus der Froschperspektive zu Hermann hinaufschauen muss. Wesentlich intensiver als die Theaterinszenierung kann der Film das Publikum einbeziehen; dieser Identifikationszwang hat eine Unmittelbarkeit zur Folge, die den Zuschauer die Position der Germanenfürsten quasi als eigene erleben lässt: ihre Unterwürfigkeit, ihre ,absolute ‘ Beantwortung der Machtfrage. Hermann schreitet langsam weiter, dadurch verändert sich sein Schatten - das Bild des Hermannsdenkmals im Teutoburger Wald -, der schließlich so groß wird, dass er die ganze Wand ausfüllt: Hermann, der Cherusker, überlebensgroß. Die Kameraeinstellung ist zwar eine Totale, aber Hermanns Abbild ist nun so groß, so total, dass es nahezu den gesamten Bildschirm einnimmt und damit wie zuvor nur die Nahaufnahme - dem Zuschauer keine Distanz mehr erlaubt; es ist keine mehr möglich: so total, so gigantisch ist Hermann nun. Der Fernsehfilm kann damit mehrere Ebenen gleichzeitig ausdrücken: Zum einen ist die Einstellung in der Totalen ganz einfach notwendig, wenn das gezeigt werden soll, was auf der Bühne zu 
Giessen, H. W. - Medienanalytische Betrachtungen

sehen ist; zum anderen ist sie aber auch selbst ein Symbol. Wenn nur noch eine Totale ausreicht, um Hermann ganz zu zeigen, demonstriert das auch, wie total und omnipotent er selbst beziehungsweise sein Mythos geworden ist. Auch im Tontrakt überdeckt die hymnenartige Musik alle Geräusche. Neben dem Mythos kann nichts bestehen.

Dann aber wird die Musik immer mehr von Gewehrsalven und anderen Kriegsgeräuschen überlagert. Die folgende Einstellung des Fernsehfilms repräsentiert diesen Wechsel, erneut in der doppelten Funktion, das Bühnengeschehen zu dokumentieren und zeigen und gleichzeitig selbst Inhaltsträger zu sein. Sie zeigt Hermann im Gegenlicht... - er ist noch immer nicht als Individuum zu erkennen, sondern als überpersönlich mythische Figur - die jetzt aber keinen Schatten mehr wirft, sondern selbst zum (noch immer gigantischen) Schatten geworden ist. Dem entspricht die amerikanische Kameraeinstellung, die bereits wieder mehr Distanz ermöglicht.

Als die Hymne schließlich vom Kriegslärm ganz überdeckt ist, brechen alle Geräusche $a b$; die Demontage erfolgt auch bei Hermann selbst: er lässt seine Kriegsutensilien (Flügelhelm, Schwert, Schild) fallen, und das Licht geht an. Mit dem Licht endet die Erscheinung des Denkmals; es konnte nur im Dunkel wirken... - Als auch der Helm zu Boden gefallen ist, geht die normale Bühnenbeleuchtung wieder an, so dass Hermann nicht mehr als Einzelner, als überpersönlicher Mythos erscheint, sondern erneut (nur) als Mensch; mehr noch: er bleibt als einsamer (nicht mehr einzigartiger), „zerstörter“ (PEYMANN 1984) (und nicht mehr verehrter und zu verehrender) Mann stehen. Dem Wechsel entspricht die Kameraeinstellung: erneut die Totale, die Hermann inmitten der großen leeren Bühne zeigt und damit dem Zuschauer wieder den Überblick ermöglicht.

Aber erneut relativiert Peymann. Zwar steht Hermann ,zerbrochen' auf der leeren Bühne, aber seine Sprache ist noch immer aggressiv; er „droht, das Drama abschließend, Rom mit Vernichtung“ (HENSEL 1982: 25), und seine letzten Worte lauten:

Wir oder unsre Enkel, meine Brüder!

Denn' eh doch, seh' ich ein, erschwingt der Kreis der Welt

Vor dieser Mordbrut keine Ruhe,

Als bis das Raubnest ganz zerstört,

Und nichts, als eine schwarze Fahne,

Von seinem öden Trümmerhaufen weht! 
PEYMANN (1984: 1) wollte den ,zerbrochenen` Sieger darstellen:

\begin{abstract}
Wir sehen zwei zerstörte Menschen. Und so sieht halt die Maske des Siegers aus. Zwei Schauspieler - auf der leeren Bühne. Die Schlacht ist geschlagen. [...] Kleist zeigt einen ganz besonderen Mann, Hermann, sich selber, den Träumer und Sucher und Gewalttäter und Mörder, der auch die Maske des Führers bekommt, der im Aufstieg zur Macht und zum Sieg sich selber zerstört. Am Ende bleibt doch ein hergelaufener Killer auf der Bühne stehen, der auch seine Frau verloren hat, vor lauter Sieg und Befreiungskrieg. [...] Stellen Sie sich Leute vor, die endlich einen Befreiungskrieg gewonnen haben und dann plötzlich den Krieg nicht mehr loswerden. Selbst ein berechtigter Krieg - wenn es das überhaupt gibt - wie der, den Hermann gegen die Römer führt oder den die Deutschen damals gegen Napoleon hätten führen sollen, selbst dieser Krieg macht das Gesicht zur Fratze; das zeigt die Melancholie und Verstörung der Schlußszene, die wir erfunden haben, wo doch nur die leere Bühne übrigbleibt und zwei Leute, bei denen fast alles kaputt ist. Und das ist eine Aussage, die wir in Kleists Stück vorfinden.
\end{abstract}

Hermann, der äußerlich vom Mythos zum Menschen degradiert worden ist, lässt verbal keine Einsicht erkennen: Alles ist so, wie es war: der Stil der Inszenierung, die Kameraeinstellung, und Hermann selbst. Seine letzten Worte sind nach wie vor Ausdruck der Zerstörungswut und des Hasses.

\title{
3.6
}

Kann das Konzept Claus Peymanns auch durch seine Bereitschaft zur Widersprüchlichkeit charakterisiert werden, so ist sein interpretatorisches Zentrum doch eindeutig (und eben durch die Kombination von Nationalismus und Macht einerseits, sowie Sexualität und Brutalität andererseits geprägt); eindeutig ist auch das selbstgestellte Ziel PEYMAnNs: „Wir müssen bei einer Aufführung eigentlich immer einen unmittelbaren Ansatz haben, einen Angelhaken für das Stück. So gab es auch einen spezifischen Bochumer Grund für die ,Hermannsschlacht': es ist eine ,Hermannsschlacht' für den Frieden.“ (1984, 1-3) Die Inszenierung erweitert daher das beschriebene Kriterienfeld (zwischen ästhetischer beziehungsweise politischer Ablehnung beziehungsweise Bewunderung):

Auch Claus Peymann scheint von der Sprache und Form Kleists fasziniert zu sein, die politische Aussage Kleists (die ja offenbar auf einen Konflikt mit den Franzosen gezielt hat) scheint er abzulehnen - aber er interpretiert den Inhalt um, indem er ihn als monströse Warnung zu verstehen vorgibt. Peymann hat also die Rezeptionsgeschichte um einen Aspekt erweitert; von daher ist seine Interpretation 
historisch bedeutsam und der eingehenden Beschäftigung (wie auch der Dokumentation im Fernsehen) wert.

\section{7}

Auch dieser neue Aspekt in der Rezeptionsgeschichte muss aus der historischen Situation heraus verstanden werden, in der er entstanden ist. Einerseits und sehr konkret ist dies die Friedensbewegung, die Ende der siebziger und Anfang der achtziger Jahre im Zusammenhang mit dem Nato-Doppelbeschluss und die durch ihn ausgelöste Kriegsangst insbesondere in Westdeutschland entstanden ist. Dabei ist unwichtig, ob diese Kriegsangst irrational gewesen oder durch objektive Gefährdungen hervorgerufen worden war - wie die Diskussion aus der Zeit deutlich macht (beispielsweise ALT 1983, Lafontaine 1983, Pestalozzi/Schlegel/Bachmann 1983, Ahlfeld 1984), ist die Angst von sehr vielen Bürgern empfunden worden. Offensichtlich bezieht sich Claus Peymann konkret auf diese historische Situation.

Andererseits verweist sein Ansatz auf die Rezeption der der zeitgenössischen Diskussionen. Zum Zeitpunkt der Peymannschen Aufführung war sie insbesondere Peter Koslowski, Wolfgang Welsch, aber auch von den frühen Schriften Peter Sloterdijks geprägt. Ein Beispiel soll dies verdeutlichen. So veröffentlichte Peter SLOTERDIJK im selben Jahr 1983 seine (auch kommerziell erfolgreiche) „Kritik der zynischen Vernunft“, in der er beispielsweise betont hat: „Im Grunde glaubt kein Mensch mehr, daß heutiges Lernen ,Probleme` von morgen löst; fast sicher ist vielmehr, daß es sie auslöst.“ (1983: 13). Claus Peymanns oben zitierter Satz, wonach auch ein ,gerechter Krieg' die Ideale zerstört, die er retten will, ist allenfalls eine Transformation dieses Diktums von Peter Sloterdijk; in der Tendenz sind beide Feststellungen deckungsgleich. Claus Peymann hat also die erste Interpretation der ,Hermannsschlacht ${ }^{\star}$ vorgelegt, die sich dem ,klassischen`Interpretationsschema entzieht.

Vermutlich war die Hinwendung zur ,Hermannsschlacht‘ erst aufgrund der damals dominierenden gesellschaftlichen Diskurse möglich. Claus Peymanns Inszenierung (und Fernsehfilm) sind demnach nicht nur für die Kleistforschung wichtige Daten, sie stellen gleichzeitig ein Indiz für die Entwicklung des Zeitgeists in Deutschland zu Beginn der achtziger Jahre dar. Um so wichtiger ist die Tatsache, dass die Peymannsche Interpretation (in der Form seines Fernsehfilms) dokumentiert werden konnte. 
Schließlich muss noch diskutiert werden, ob eine solche Interpretation der ,Hermannsschlacht‘ überhaupt sinnvoll und möglich ist.

Claus Peymann will zeigen, dass jeder Krieg, ob man ihn als Sieger oder Verlierer übersteht, immer zerstörende und vernichtende Folgen hat. Um seine Überzeugung zu verdeutlichen, stellt er die mit dem Krieg verbundenen Grausamkeiten (der Germanen) explizit, geradezu überdeutlich dar. In der Verbindung von Brutalität und Sexualität erhält der Krieg aber eine nicht rationale, sondern anthropologische Grundlage. Keine Person, die die Inszenierung portraitiert, entzieht sich diesem Schema, das zudem nicht begründet, sondern als gegeben gezeigt wird. So scheint es unmöglich zu sein, an den festen, zeitlosen Strukturen (die, wie die anachronistischen Kostüme demonstrieren, seit dem Altertum über die nachrevolutionären Kriege bis heute gelten) etwas ändern zu können. Damit ist aber auch die Möglichkeit fragwürdig geworden, selbst durch Aufzeigen der Strukturen ihre Existenz und Wirksamkeit zu beeinflussen.

Gerade dies scheint aber das Ziel Claus Peymanns gewesen zu sein: gemäß seiner Absicht, dem Frieden zu dienen.

Wie bereits dargestellt worden ist, hat Claus Peymann seine Umdeutung vor allem dadurch zu erreichen versucht, dass er die Originalaussage durch eine negative Symbolik permanent relativiert, dass er also dem Stück widerspricht - allerdings nur inhaltlich, nicht in Bezug auf die Form oder Sprache. Dieses Verfahren ist problematisch und nur als Symbol möglich, denn die Handlungen der Personen werden noch immer - und bei Peymann, der ja sehr viel Achtung vor der Kleistschen Sprache und Form zeigt, sogar sehr eindringlich - durch den Originaltext begründet. Die ,Hermannsschlacht` rechtfertigt aber den Krieg - eine entgegengesetzte Interpretation ist mithin nahezu unmöglich. Werden die ,rationalen` Gründe, die das Stück selbst liefert, dennoch hinterfragt, aber keine anderen ,rationalen“ Gründe für das Handeln der Personen entwickelt, dann bleiben nur die strukturellen, anthropologischen Gründe bestehen.

Offensichtlich hat Peymann seine Umdeutung auch dadurch $\mathrm{zu}$ erreichen versucht, dass er sämtliche Hauptpersonen der Lächerlichkeit preisgegeben hat - 
Giessen, H. W. - Medienanalytische Betrachtungen

Peymann läßt keinen Zweifel, daß die Taten des Guerillero Hermann blutig sind, doch wo er Gelächter herausschlagen kann, da schlägt er unerbittlich zu, und besonders genießt er es, wenn er Gewalt und Gelächter zusammenzwingt: wenn die Römer über die Sümpfe schlittern; wenn ihre gesichtslose Armee als choreographische Gruppe im Kampfe wankt und im Tod erstarrt. Schlimme Gewalt und schlimmes Gelächter: wenn der gefangene Römer Septimius sich auf sein Recht beruft und Hermann ihn dennoch totschlagen läßt; wenn Hermann über das Recht des Gefangenen höhnisch lacht und das Publikum mit ihm. (HENSEL 1982: 25)

- aber auch dieses Gelächter erklärt nichts; es gibt dem Lachenden nur das Gefühl, über den lächerlichen Personen zu stehen (oder es drückt gar ein erkennendes Einverständnis aus). Wenn aber Sadismus und Masochismus tatsächlich universelle Phänomene sind, gibt es - vor dem Hintergrund der Absicht, für den Frieden zu wirken - keinen Grund, es dem Publikum zu ermöglichen, sich unschuldig oder einverständlich zu fühlen.

So bleibt die Einsicht, dass strukturelle, anthropologische Gründe allein den Krieg zu erklären in der Lage sind - und mit ihr das Problem, dass ein Widerspruch entsteht zwischen dem Wunsch, dem Frieden zu dienen, und dem interpretatorischen Ansatz, der Peymannschen Sicht auf die ,Hermannsschlacht', der die Unmöglichkeit impliziert, Frieden überhaupt als realisierbar erscheinen zu lassen. Der emotionale Eindruck C. Bernd Suchers von der Premiere weist in dieselbe Richtung, wie bereits seine Überschrift (,Rettung? - Warten auf den Untergang“) belegt.

\section{9}

Offensichtlich mündet Claus Peymanns neuer Ansatz in eine Sackgasse - immerhin bleibt sein Verdienst, ihn gewagt zu haben; allein dies setzt seinen Versuch ins Recht. Damit hat Peymann auch die Notwendigkeit belegt, die bisher die ,Hermannsschlacht ${ }^{6}$ Rezeption dominierende Schematik zu durchbrechen und sich ihrem Kriteriensystem zwischen Form und Inhalt zu entziehen.

\section{Literaturverzeichnis}

AdoRno, TH. W., „Die Freudsche Theorie und die Struktur faschistischer Propaganda“, in: Kritik. Kleine Schriften zur Gesellschaft, Frankfurt/M.: Suhrkamp 1971

AFHELDT, H., Atomkrieg. Das Verhängnis einer Politik mit militärischen Mitteln, München, Deutscher Taschenbuch Verlag, 1984

ALBERTI, C., „Die Hermannsschlachtung“, in: Zukunft Vol. VI., 25, 1894 
AllemanN, B., „Der Nationalismus Heinrich von Kleists“, in: MÜLlER-SEIDEL, W. (Hrsg.), Kleists Aktualität, Darmstadt, Wissenschaftliche Buchgesellschaft, 1981, 46 - 54.

ALt, F., Frieden ist möglich, München, Piper,13. Auflage, 1983

BARDONG, O. „Hambacher Fest und Wartburgfest - Freiheit und Einheit für die Deutschen“, in: Studia historica Nitriensia 1, 1993, 9 - 25.

Berger, H., BÖtTcher, K., Hoffmann, L., NAumanN, M. (Hrsg.), Schauspielführer, Berlin, Henschel, Band II/1, 1975.

BLÖCKERS, G., Heinrich von Kleist oder Das absolute Ich, Berlin, Fischer, 1960

BraHM, O., Das Leben H. v. Kleists, Berlin, Fleischel, 1884

ColLIN, M. von, „Über neuere dramatische Literatur“, in: Jahrbuch der Literatur XX., Wien: Gerold 1822, $111-125$.

FISCHER, E., „Heinrich von Kleist“, in: Sinn und Form, Heft 5/6, 1961, 759 - 844.

GIESSEN, H. W., Medienadäquates Publizieren. Von der inhaltlichen Konzeption zur Publikation und Präsentation. Berlin; Heidelberg: Spektrum Akademischer Verlag / Elsevier 2004

GRABBE, Chr. D., Die Hermannsschlacht, Düsseldorf 1838, zitiert nach dem Digitalisat der Lippeschen Landesbibliotghek Detmold (http://s2w.hbznrw.de/llb/content/titleinfo/590837, 19. Juli 2013)

Grunewald, M., „Heinrich von Kleist, Die Hermannsschlacht“, in: Deutsches Adelsblatt XXXXIII., 1925

GuNDOLF, F., Heinrich von Kleist, Berlin, Bondi, 1924

GuTZKow, K., Dionysius Longinus, Oder: Über den ästhetischen Schwulst in der neueren deutschen Literatur, Stuttgart, Gutzkow, 1878

Hembus, J., Der deutsche Film kann gar nicht besser sein, München, Heyne, 1981

HEMPEL, G., Heinrich von Kleists Hermannsschlacht, Erlangen, Univ. Diss, 1930

HENRICHS, B., „Das anmutige Monster, Kleist. Claus Peymann entdeckt ein neues, altes Stück: ,Die Hermannsschlacht'“, in: Die Zeit Nummer 47, Hamburg, 19. November 1982, Seite 45.

HENSEL, G., Spielplan, Berlin, List, Teil 1, 1966

HENSEL, G., „Che Guevara im Teutoburger Wald, ,Die Hermannsschlacht' von Kleist, inszeniert von Claus Peymann in Bochum", in: Frankfurter Allgemeine Zeitung (FAZ), Nummer 263, Frankfurt am Main, Freitag, 12. November 1982, Seite 25.

HoHoff, C., Heinrich von Kleist in Selbstzeugnissen und Dokumenten, Hamburg, Rowohlt, 1958

HorN, P., Kleist-Chronik, Königstein, Athaeneum, 1980,

Hutten, U. von, Arminius. Dialogus Huttenicus, quo homo patriae amantissimus, Germanorum laudem celebravit, Hagenau 1529, zitiert nach dem Digitalisat der Lippeschen Landesbibliotghek Detmold (http://s2w.hbznrw.de/llb/content/titleinfo/590837, 19. Juli 2013)

IDE, H., „Kleist im Niemandsland?“, in: MÜLLER-SEIDEL, W. (Hrsg.), Kleist und die Gesellschaft. Berlin, Schmidt, 1965, 33 - 66.

KITTLER, W., Die Geburt des Partisanen aus dem Geist der Poesie: Heinrich von Kleist und die Strategie der Befreiungskriege. Freiburg: Rombach

KLEIST, H. V., Die Hermannsschlacht. Berlin 1821 (zitiert nach der Ausgabe im Projekt Gutenberg, http://gutenberg.spiegel.de/buch/577/1, 19. Juli 2013)

KLOPSTOCK, Fr. G., Hermanns Schlacht, Ein Bardiet für die Schaubühne, Bremen 1769

KosLOwsKI, P., Die postmoderne Kultur, Gesellschaftlich-kulturelle Konsequenzen der technischen Entwicklung, München, Beck, 1987 
Giessen, H. W. - Medienanalytische Betrachtungen

Lafontaine, O., Angst vor den Freunden. Die Atomwaffenstrategie der Supermächte zerstört die Bündnisse, Reinbek bei Hamburg: Rowohlt 1983

LOHENSTEIN, D. C. von, Großmüthiger Feldherr Arminius oder Hermann, Als ein tapfferer Beschirmer der deutschen Freyheit, Nebst seiner Durchlauchtigten Thußnelda In einer sinnreichen Staats- Liebes- und Helden-Geschichte Dem Vaterlande zu Liebe Dem deutschen Adel aber zu Ehren und rühmlichen Nachfolge In Zwey Theilen vorgestellet, Leipzig 1689/90

LuKÁCS, G., Die Tragödie Heinrich von Kleists, zitiert nach der Ausgabe: LuKÁCS, G., Deutsche Literatur in zwei Jahrhunderten, Neuwied, Berlin: Luchterhand 1964.

MAYER, H., Heinrich von Kleist, Der geschichtliche Augenblick, Pfullingen, Neske, 1962

Pestalozzi, H. A. Schlegel, R., Bachmann, M (Hrsg.), Frieden in Deutschland. Die Friedensbewegung: wie sie wurde, was sie ist, was sie werden kann, München, Goldmann, 1982;

PeYmanN, C. „Die Hermannsschlacht” nach Heinrich von Kleist, Zweites Deutsches Fernsehen, Fernsehproduktion 1984

PeymanN, C., „Eine „Hermannsschlacht“ für den Frieden“, in: Theater Heute, Heft 1, 1984, 1 3.

PFITZNER, H., „Die Hermannsschlacht“, Mainz, Schott, 1915

PindeMonte, I., Arminio, Verona 1804

QUARK, M., „Ein preußischer Junker als dichterischer Revolutionär“, in: Sozialistische Monatshefte, 1902

SCHÄFER, R., „Der gefälschte Brief, Eine unkonventionelle Hypothese zu Kleists ,Hermannsschlacht"“, in: Kleist-Jahrbuch 1993, 181 - 189.

SCHMIDT, J., „H. v. Kleist“, in: Preußische Jahrbücher, 1876, 593 - 607.

SENGLE, F., Das deutsche Geschichtsdrama, Stuttgart, Metzler, 1952

SLOTERDIJK, P., Kritik der zynischen Vernunft, Frankfurt am Main: Suhrkamp, Band I, 1983

Streller, S., „Anmerkungen“, In: STRELler, S. (Hrsg.), H. v. Kleist, Werke und Briefe, Berlin, Weimar, Band 2, 1978

SUCHER, C. B. „Rettung? - Warten auf den Untergang. Claus Peymanns radikale neue Deutung von Kleists ,Hermannsschlacht' in Bochum“, in: Süddeutsche Zeitung (SZ) Nummer 261, München, Freitag, 12. November 1982, Seite 12.

TACITUS, De origine et situ Germanorum liber, zitiert nach der Ausgabe Stuttgart, Reclam, 1971

TIECK, L., Hinterlassene Schriften von Heinrich von Kleist, Berlin, Reimer, 1821

TraumanN, E. „Goethe, der Straßburger Student“, Leipzig Klinkhardt \& Biermann 1923.

TreitschKe, H. v., „Kleist“, in: Preußische Jahrbücher, 1858, 599 - 623.

VInKEn. B., Bestien. Kleist und die Deutschen, Berlin: Merve 2011

WELSCH, W., Unsere postmoderne Moderne, Weinheim: VHC 1987

WILLBRANDT, A., H. V. Kleist, Nördlingen 1863

WINKLER, H. A. (Hrsg.), Nationalismus, Meisenheim, Hain, 1978

Zolling, Th., „Anmerkungen“, in: Zolling, Th., Kleists sämtliche Werke, Berlin, Stuttgart, Speemann, 3. Teil 1885.

ZWEIG, S., Der Kampf mit dem Dämon, Leipzig, Insel, 1925

Recebido em 20/07/2013

aceito em 23/09/2013 